\title{
Gray-box model of inland navigation channel: Application to the Cuinchy-Fontinettes reach
}

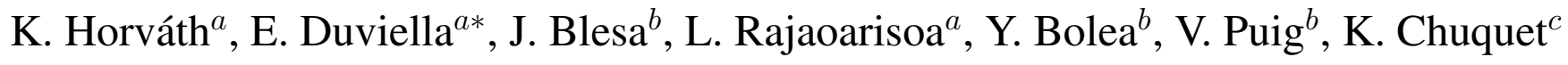 \\ a: Mines-Telecom Institute, Mines Douai, France \\ b: Universitat Politecnica de Catalunya, Automatic Control Department, Spain \\ c: VNF - Service de la navigation du Nord Pas-de-Calais, France \\ *Cor. Author: eric.duviella@mines-douai.fr
}

September 14, 2013

\begin{abstract}
In a context of global change, the inland navigation transport has gained interest with economic and environmental benefits. The development of this means of conveyance requires the improvement of its management rules to deal with the increase of navigation (schedules and frequency) and the potential impact of global change. To achieve this aim, it is firstly necessary to have a better knowledge about the dynamics of inland navigation networks and their interaction with the environment. Secondly, the potential effects of global change have to be anticipated. This paper focuses on the modeling of inland navigation reaches. An inland navigation network is a large scale distributed system composed of several interconnected reaches. These reaches are characterized by non-linearities, time-delays and generally no significant slope. To deal with these particularities, a gray-box model is proposed. It consists in determining the delays according to physical characteristics of the systems. The parameters of the model are identified with measured data. The gray-box model is used to reproduce the dynamics of the Cuinchy-Fontinettes reach located in the north of France.
\end{abstract}

1

2

3

4

5

6

7

8

9 


\section{Introduction}

The alternative which is offered by the transport using inland navigation networks appears to be increasingly interesting in a global change context. This means of transport provides economic and environmental benefits $(29,28)$ by offering access to the urban and industrial centers of the continent, and allowing an efficient, quieter, and safer transport of goods (5). Inland navigation networks in the north of Europe are developping to accommodate large broad gauge boats and to increase the navigation schedules. In this way, it is more than $42,000 \mathrm{~km}$ of canals, rivers and canalized rivers which can benefit to the progress on Information and Communication Technology (ICT), such as new sensors and actuators (6; 16), or SCADA (Supervisory Control and Data Acquisition) systems. This last decade, SCADA systems have been developped for inland navigation systems (7; 36), and for irrigation canals (32; $27 ; 34)$, to improve their control $(31 ; 22)$, their maintenance and their security (1). More and more inland navigation networks are modernizing by the implementation of SCADA systems. These networks are telecontrolled with the main objective to insure the seaworthiness requirements for the accommodation of the broad gauge boats. The seaworthiness is insured by the maintain of the water level of the navigation channels close to a Normal Navigation Level (NNL). The control of the water levels is complex due to the increasing of the gauge of the boats and of the navigation schedules, but mainly to extreme events due to global change. In effect, longer periods of drought and stronger and more frequent flood events are expected in the future. The effects and consequences of global change are studied for several years, taking into account social, economic and environmental aspects (10; 18, 30). In particular, starting from meteorological models at the planetary scale, climatic scenarios have been built to forecast the future state of the water resource on horizons from 10 years to 100 years. In addition of a greater frequency and intensity of extreme weather events, these future projections suggest the increase of the water temperature and the modification of river morphology. These conclusions are shared by studies of the impact of global change of the main French river basins (4; 11), of the Mediterranean basin in (17), basins in U.K. (19; 2) and China (35). The PIANC ${ }^{1}$ organisation published a report by considering various projected scenarios on waterways (15). It highlights the future stronger constraints linked to water supply and quality in inland navigation. These studies propose some measures for adapting the management of inland navigation networks in global change context. For waterway operation, it is recommended to improve the management of water flow and to propose decision support systems which gather adaptive management strategies. Following these recommendations, an adaptive and predictive control architecture for the management of inland navi-

\footnotetext{
${ }^{1}$ Permanent International Association of Navigation Congresses
} 
gation networks has been proposed in (13). This architecture aims at studying the resilience of inland navigation networks against extreme climate events, and to improve the management rules. In consequence, it requires a model of inland navigation networks. Generally, inland navigation networks cover several watersheds and are supplied with water by natural inflow. They are composed by interconnected canalized rivers and artificial channels separated by locks. Each part of a river or a channel between two locks is refered as navigation reach. These reaches are large open-channel systems with no significant slope and characterized by multi-inputs-multi-ouputs (MIMO) and time-delays. Moreover, they can be affected by resonance waves. An inland navigation reach can be modeled by the Saint-Venant Partial Differential Equations (8) whose solution involves numerical approaches according to discretization scheme. These numerical approaches are rather complex to handle in the control, Fault Detection and Isolation (FDI) or management strategy design. On the other hand, the modeling techniques based on the simplification and linearization of the Saint-Venant equations such as in (23), might not be applicable to MIMO systems and they can not reflect the wave phenomenon. In (3), a control algorithm based on Model Predictive Control (MPC) is proposed to model a navigation reach with the aim to compensate or to reduce the waves impacting the reach. But the proposed model is only dedicated for control algorithm design. An alternative consists in proposing modeling approaches based on system identification techniques. Due to the importance of the transfer-delays, it is easier to have an a priori knowledge of them or to use a preliminary estimation technique according to the measurements on the system. Thus, this approach consists in a gray-box modeling (12). Gray box modeling is a popular approach for modeling real systems, combining both black box and white box methodologies (33). It has the advantage of using both physical a priori knowledge of the system for model structure development, and parameter estimation from available experimental data. That is, gray box modeling of systems involves constructing a model structure based on physical knowledge of the system and model identification using estimation methods. In this paper, a gray-box modeling approach for MIMO time-delay open-channel systems is proposed. It is based on identification techniques that use data from measurements. This modeling approach is used to reproduce the dynamics of the Cuinchy-Fontinettes Reach (CFR). The CFR is an inland navigation reach located in the north of France. When the CFR locks are operated, a wave is created that is able to travel several times back and forth in the reach. These waves can be more than ten centimeters high. The structure of the paper is the following: Section II is dedicated to the description of an adaptive and predictive control architecture for the management of inland navigation network and the proposition of the gray box modeling approach. In Section III, the CFR is described and the gray box modeling approach is applied to it. The effectiveness of the proposed modeling approach is shown using a 1D hydrodynamic software based 


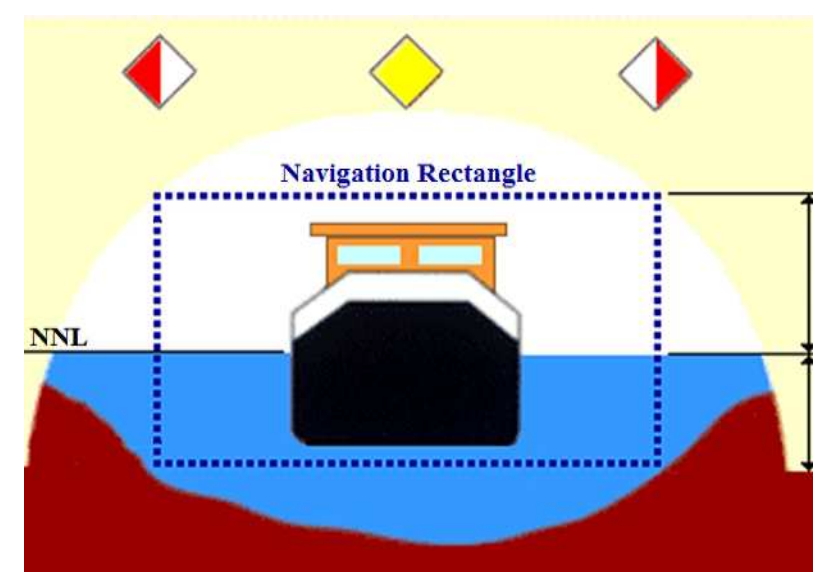

Figure 1: Normal Navigation Level inside the navigation rectangle.

on Saint-Venant equations (26) in Section IV. Finally, some conclusions are drawn in Section V.

\section{Background}

\subsection{Adaptive and predictive control architecture}

The main management objective of the inland navigation networks is to guarantee the seaworthiness requirement of each reach, i.e. the Normal Navigation Level (NNL) (see Figure 1). These levels are principally disturbed by the navigation and the lock operations. During lock operations, large volume of water is withdrawn from the upstream reach and supplied to the downstream reach causing a wave to travel to both directions; upstream to downstream, and downstream to upstream after reflection. Generally, these waves are not significant. But sometimes, due to the dimension of the locks, the amplitude of the wave exceeds several tens of centimeters. This wave is reflected at the downstream end of the channel and travels several times back and forth. To reduce the effect of wave and to maintain the NNL, it is necessary to control the gates which are generally located beside the locks. Another possibility is to control the discharges from natural rivers. The water levels are controlled by gates and measuerd by tele-operating sensors. The management rules have to consider other strong constraints during drought and wet periods. During drought periods, the water for industry, agriculture, ecological aims and drinking water, has bigger priority than the water for navigation. Some restrictions on navigation can be imposed during these periods. The navigation is managed by the planning of ship conveys. However, the locks and gates have to be operated to maintain a minimal water flow (ecological flow) in order to decrease the water temperature, to increase the oxygen rate in the water 


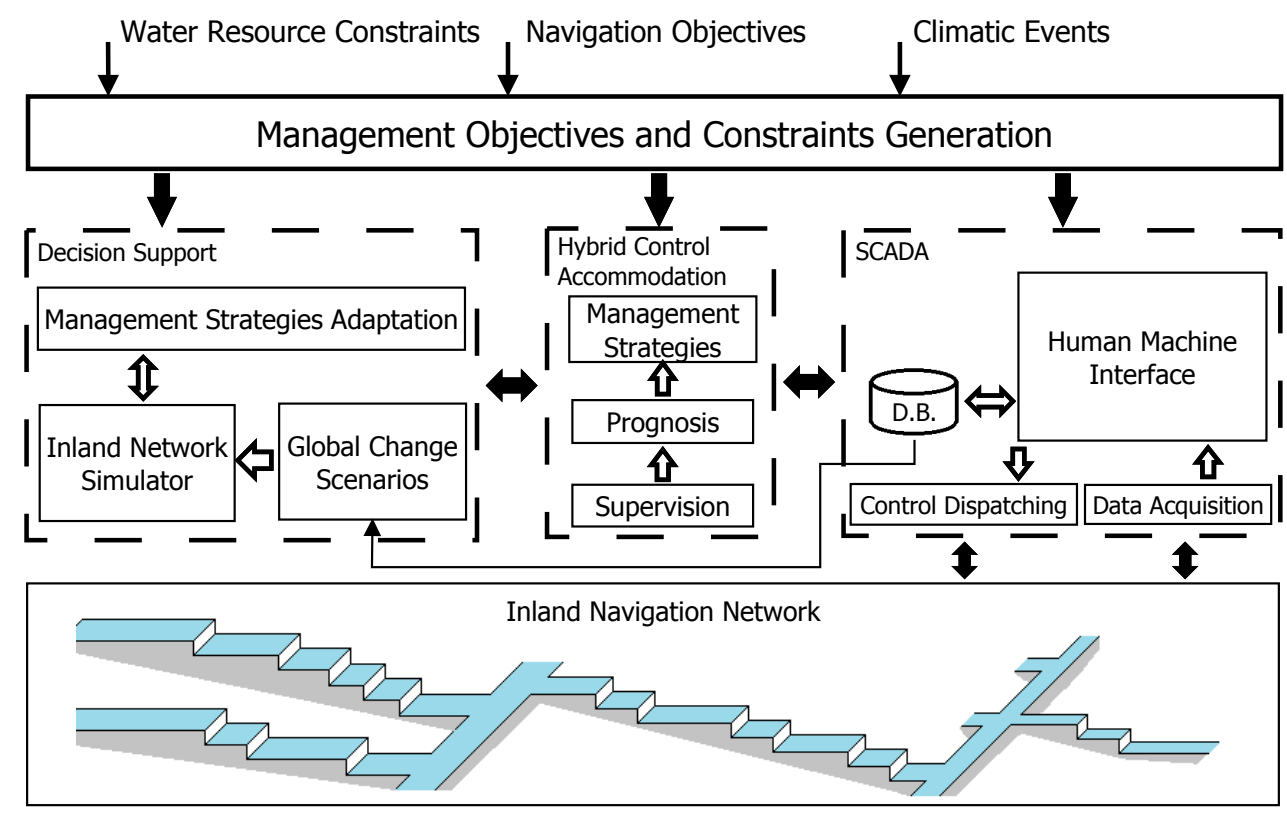

Figure 2: Adaptive and predictive control architecture.

and to limit the modification of the ecosystem, such as the development of algae. During wet periods, some management protocols have to be applied. By experience, the navigation reaches are supplied by natural rivers even if the locks and gates are closed. So, before the occurrence of wet events, the level of each navigation channel is decreased and their gates and locks are closed. The gates or the locks are operated only when the level of the reaches attained a critical limit beyond which the banks can be damaged. The amplitude and the frequency of extreme scenarios of drought and flood should be increased in the future as a consequence of global change. It is thus necessary to anticipate the effects of these events on the navigation reaches, by a study of their resilience and by the proposal of improved management strategies. To achieve these aims, an adaptive and predictive control architecture has been proposed in (13) as depicted in Figure 2. This architecture is based on a SCADA system allowing the tele-control of the navigation network. A Human Machine Interface (HMI) is dedicated to the supervision of the inland navigation network by a supervisor. The management constraints and rules are gathered in the Management Objectives and Constraints Generation module (MOCG). To perform the management of the inland navigation network, a Hybrid Control Accommodation module (HCA) 


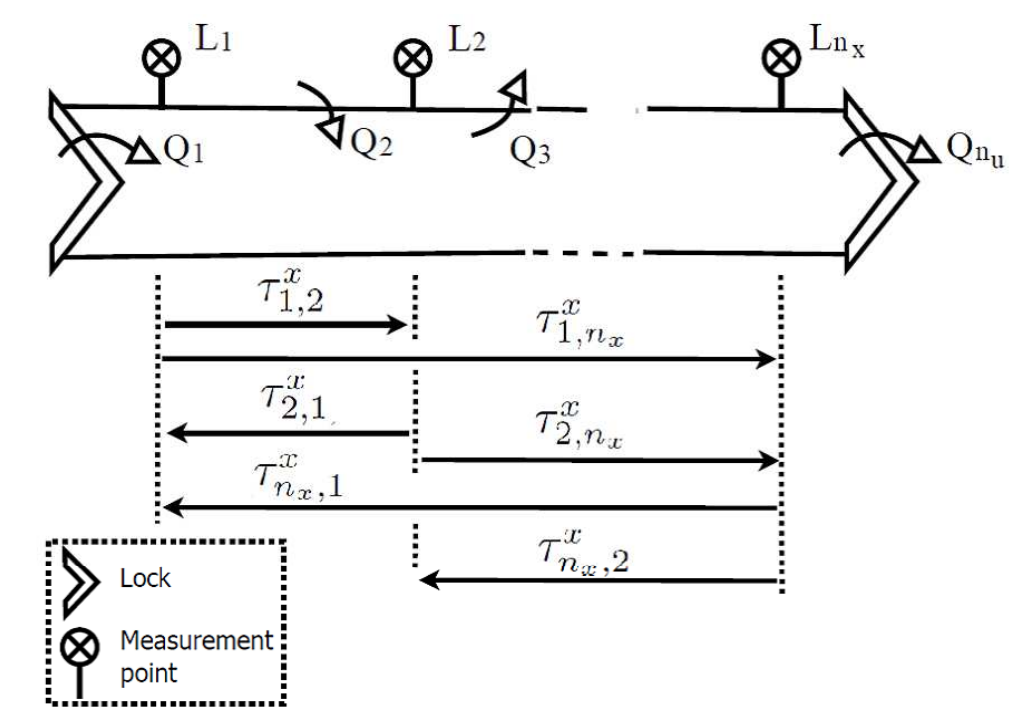

Figure 3: Time delays $\tau_{i, j}^{y}$ between each measurement point

to test the resilience of the network against extreme scenarios, and to design adaptive management strategies. In a first step, this module is used offline. Realistic scenarios of extreme events are built according to past events and to the knowledge on global change consequences. They are tested on a simulator of inland navigation networks. Thus, the DS module requires models of the dynamics of the inland navigation networks.

\subsection{Inland navigation reach modeling}

The modeling of inland navigation reaches is necessary to design adaptive and predictive management strategies, control algorithms and FDI techniques such as proposed in (20; 14). A navigation reach belongs to the class of open-channel systems with the particularity of very mild slope. By considering the operating points corresponding to the NNL, the dynamics of a reach can be modeled by a linear model. The structure of the model is selected in order to be suitable for the design of control strategies, FDI algorithms, etc., and particularly for MIMO systems. The proposed modeling approach assumes a first order plus time delay structure for every input/output pair. The output variables are chosen as the $n_{y}$ measured water levels $L_{i}(k)$ in several selected points of the system. The input variables of the model correspond to the $n_{u}$ input/output discharges $Q_{l}(k)$ (see Figure 3). Finally, time delay matrices $\tau^{y}$ and $\tau^{u}$ are considered for each output and input variables of the model to take into account the transfer delays of the reach leading to the following model 


$$
y_{k+1}=A \bar{y}_{k \mid \tau^{y}}+B \bar{u}_{k \mid \tau^{u}}
$$

where matrices $A \in \mathbb{R}^{n_{y} \times n_{y} \cdot n_{y}}$ and $B \in \mathbb{R}^{n_{y} \times n_{u} . n_{y}}$ are the input and output matrices, respectively. At each time $k$, the vector $\bar{u}_{k \mid \tau_{i}^{u}} \in \mathbb{R}^{n_{u} \cdot n_{y}}$ representing the input variable is defined according to the delay matrix $\tau^{u}$ and the vector $\bar{y}_{k \mid \tau^{y}} \in \mathbb{R}^{n_{y} \cdot n_{y}}$ representing the delayed output variables according to the delay matrix $\tau^{y}$. The matrices $\tau^{y} \in \mathbb{N}^{n_{y} \times n_{y}}$ and $\tau^{u} \in \mathbb{N}^{n_{u} \times n_{y}}$ gather the time delays between each measurement point (see Figure 3), and between each measurement point and each input and output of the system, respectively. For example, the value of $\tau_{i, j}^{y} \in \mathbb{N}$ is the time delay between the measurement points $L_{i}$ and $L_{j}$.

$$
\tau^{y}=\left[\begin{array}{cccc}
0 & \tau_{1,2}^{y} & \cdots & \tau_{1, n_{y}}^{y} \\
\tau_{2,1}^{y} & 0 & \cdots & \tau_{2, n_{y}}^{y} \\
\vdots & \vdots & \ddots & \vdots \\
\tau_{n_{y}, 1}^{y} & \tau_{n_{y}, 2}^{y} & \cdots & 0
\end{array}\right]
$$

The time delays $\tau_{i, j}^{y}$ are equal to 0 for $i=j$. The time delay matrices $\tau^{y}$ and $\tau^{u}$ are supposed to be known and constant.

The elements of the matrices $\tau^{y}$ and $\tau^{u}$ can be obtained a priori by correlation methods (databased procedure) or from the physical knowledge of the system. Consider two points along the canal, separated by a distance $D$ : upstream and downstream points. According to (21), the theoretical value of the upstream time delay between these two points is evaluated by computing the integral:

$$
\tau_{u p}=\int_{0}^{D} \frac{d l}{c(l)+v(l)}
$$

with $c(l)$ and $v(l)$ representing the celerity and the velocity respectively. This corresponds to the minimum time required for a perturbation to travel from the upstream point to the downstream point. Analogously, the downstream time delay $\tau_{d w}$ can be evaluated by:

$$
\tau_{d w}=\int_{0}^{D} \frac{d l}{c(l)-v(l)}
$$

and corresponds to the maximum time required for a perturbation to travel from the downstream point to the upstream point. In both cases, we recover the classical value in the uniform case when $v$ and $c$ are constant: $\tau_{u p}=\frac{D}{c+v}$ and $\tau_{d w}=\frac{D}{c-v}$, with $c=\sqrt{g \frac{S}{b}}$ and $v=\frac{Q}{S}$. The cross sectional area $S$ and the bottom width $b$ are chosen constant as the mean values, $g$ is the gravity and $Q$ is the average flow of the canal. The vector $y_{k}$ in (1) is:

$$
y_{k}=\left[L_{1}(k) L_{2}(k) \cdots L_{n_{y}}(k)\right]^{T}
$$


Thus, the vector $\bar{y}_{k \mid \tau^{y}}$ is built according to the matrix $\tau^{y}$ such as:

$$
\begin{aligned}
\bar{y}_{k \mid \tau^{y}}= & {\left[L_{1}\left(k-\tau_{1,1}^{y}\right) L_{2}\left(k-\tau_{1,2}^{y}\right) \cdots L_{n_{y}}\left(k-\tau_{1, n_{y}}^{y}\right)\right.} \\
& L_{1}\left(k-\tau_{2,1}^{y}\right) L_{2}\left(k-\tau_{2,2}^{y}\right) \cdots L_{n_{y}}\left(k-\tau_{2, n_{y}}^{y}\right) \\
& \left.\cdots L_{n_{y}}\left(k-\tau_{n_{y}, n_{y}}^{y}\right)\right]^{T}
\end{aligned}
$$

The vector $\bar{u}_{k \mid \tau^{u}}$ is built according to the matrix $\tau^{u}$ similarly as relation $(6)$ :

$$
\begin{aligned}
\bar{u}_{k \mid \tau^{u}}= & {\left[Q_{1}\left(k-\tau_{1,1}^{u}\right) Q_{2}\left(k-\tau_{1,2}^{u}\right) \cdots Q_{n_{u}}\left(k-\tau_{1, n_{u}}^{u}\right)\right.} \\
& Q_{1}\left(k-\tau_{2,1}^{u}\right) Q_{2}\left(k-\tau_{2,2}^{u}\right) \cdots Q_{n_{u}}\left(k-\tau_{2, n_{u}}^{u}\right) \\
& \left.\cdots Q_{n_{u}}\left(k-\tau_{n_{y}, n_{u}}^{u}\right)\right]^{T}
\end{aligned}
$$

The input and output matrices are defined as:

$$
\begin{aligned}
A & =\left[\begin{array}{cccccccccc}
a_{1}^{1} & a_{2}^{1} & \cdots & a_{n_{y}}^{1} & 0 & 0 & \cdots & 0 & \cdots & 0 \\
0 & 0 & \cdots & 0 & a_{1}^{2} & a_{2}^{2} & \cdots & a_{n_{y}}^{2} & \cdots & 0 \\
\vdots & \vdots & \ddots & \vdots & \vdots & \vdots & \ddots & \vdots & \ddots & \vdots \\
0 & 0 & \cdots & 0 & 0 & 0 & \cdots & 0 & \cdots & a_{n_{y}}^{n_{y}}
\end{array}\right] \\
B & =\left[\begin{array}{cccccccccc}
b_{1}^{1} & b_{2}^{1} & \cdots & b_{n_{u}}^{1} & 0 & 0 & \cdots & 0 & \cdots & 0 \\
0 & 0 & \cdots & 0 & b_{1}^{2} & b_{2}^{2} & \cdots & b_{n_{u}}^{2} & \cdots & 0 \\
\vdots & \vdots & \ddots & \vdots & \vdots & \vdots & \ddots & \vdots & \ddots & \vdots \\
0 & 0 & \cdots & 0 & 0 & 0 & \cdots & 0 & \cdots & b_{n_{u}}^{n_{y}}
\end{array}\right]
\end{aligned}
$$

After the structure of the model has been defined, the objective is to identify the matrices $A$ and $B$. Model (1) can be rewritten as:

$$
\hat{y}_{k+1}=M \Phi_{k}
$$

with $M=[A B]$ and $\Phi_{k}=\left[\bar{y}_{k \mid \tau^{y}} \bar{u}_{k \mid \tau^{u}}\right]^{T}$. Then, the matrix $M$ has to be determined according to an identification approach using available measured data. The data correspond to $N$ samples of the discharges $Q_{i}$ and levels $L_{i}$ measured on a time interval. Based on relation (10), the matrix $M$ is estimated in the following way:

$$
\hat{M}=Y \bar{\Phi}^{T}\left(\bar{\Phi} \bar{\Phi}^{T}\right)^{-1}
$$

with $Y=\left[\begin{array}{lll}y_{T+1} & \cdots & y_{N}\end{array}\right], \bar{\Phi}=\left[\begin{array}{lll}\bar{\Phi}_{T} & \cdots & \bar{\Phi}_{N-1}\end{array}\right]$, and $T=\max \left(\tau^{y}\right)+1$ where $\max \left(\tau^{y}\right)$ being the maximum entry of the matrix $\tau^{y}$ (see relation (2)). 
Considering the characteristics of the matrices $A$ and $B$, and the size of $Y$ and $\bar{\Phi}$, it is easier to identify separately each line of $M$, before rebuilding the global matrices $A$ and $B$. The zeros of matrices $A$ and $B$ are not considered during the identification step. It is based on the principle that each output variable can be expressed such as the first output variable:

$$
\begin{aligned}
& L_{1}(k+1)=a_{1}^{1} L_{1}\left(k-\tau_{1,1}^{y}\right)+a_{2}^{1} L_{2}\left(k-\tau_{1,2}^{y}\right)+\cdots \\
& +a_{n_{y}}^{1} L_{n_{y}}\left(k-\tau_{1, n_{y}}^{y}\right)+b_{1}^{1} Q_{1}\left(k-\tau_{1,1}^{u}\right) \\
& \quad+b_{2}^{1} Q_{2}\left(k-\tau_{1,2}^{u}\right)+\cdots+b_{n_{u}}^{1} Q_{n_{u}}\left(k-\tau_{1, n_{u}}^{u}\right)
\end{aligned}
$$

Using this particular structure of the model, the dynamics of a real navigation reach can be identified. The Cuinchy-Fontinettes reach is presented in the next section.

\subsection{Presentation}

In the north of France, the inland navigation network allows the navigation of broad gauge ships from the regions in the north of Paris to the port of Dunkerque and to Belgium. This network covers three watersheds: the Aa, the Lys and the Scarpe watersheds (see Figure 4). Due to the topography, the canalized rivers and channels are separated by locks which allow the navigation. The Cuinchy-Fontinettes navigation reach (CFR) is located in the center of the network, between the upstream lock of Cuinchy at the East of the town Bethune and the downstream lock of Fontinettes at the Southwest of the town Saint-Omer. The CFR has a major importance for the management of this inland navigation network. The first part of the CFR, i.e. $28.7 \mathrm{~km}$ from Cuinchy to Aire-sur-la-Lys, is called 'canal d'Aire' and has been built in 1820 (see Figure 5). The second part of the channel, i.e. $13.6 \mathrm{~km}$ from Aire-sur-la-Lys to Saint-Omer, is called 'canal de Neuffossé' and has been built in the eleventh century. The direction of the flow is from Cuinchy to Fontinettes. The CFR is entirely artificial without significant slope and with 614 different transversal cross sections which have to be considered. The CFR is managed by VNF (Voies Navigables de France) whose role is to maintain the level of the channel at $N N L=19.52$ NGF (Nivellement Général de la France, i.e. altitude landmark in France). To reach this aim, three points of the CFR must be controlled:

- At Cuinchy; a lock and a gate which are located side by side,

- At Aire-sur-la-Lys; the gate called 'Porte de Garde',

- At Fontinettes; a lock. 


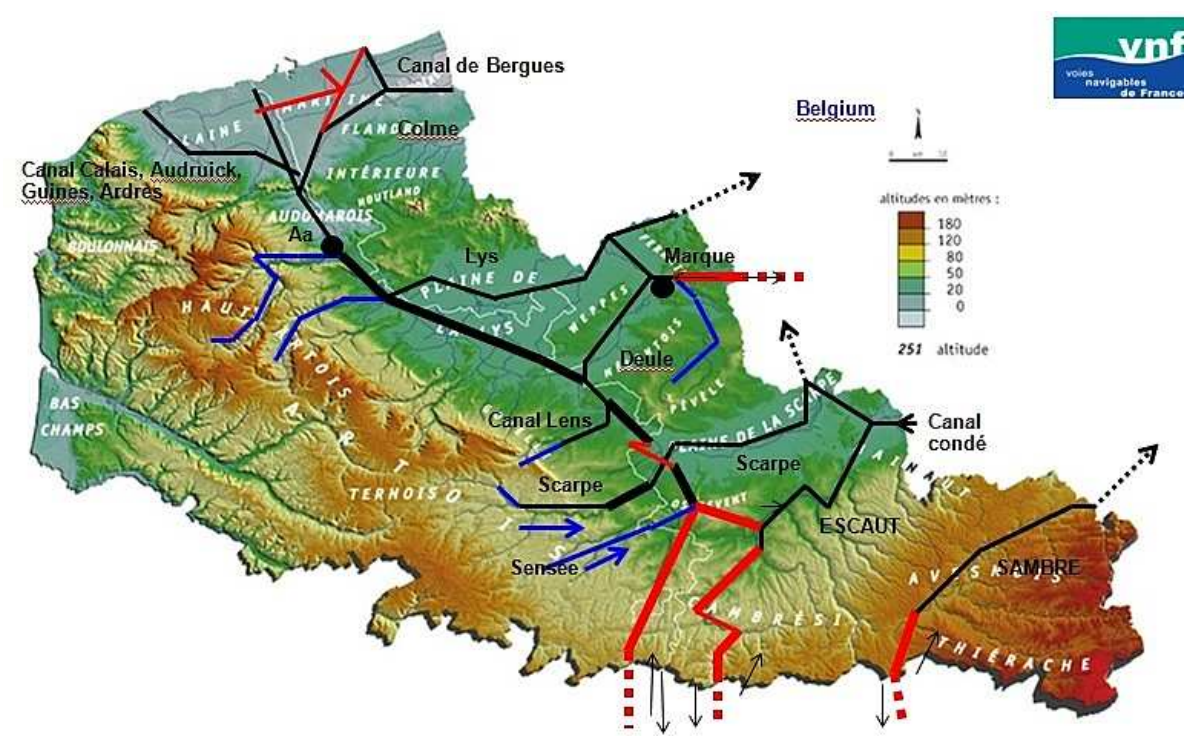

Figure 4: Inland navigation network in the north of France.

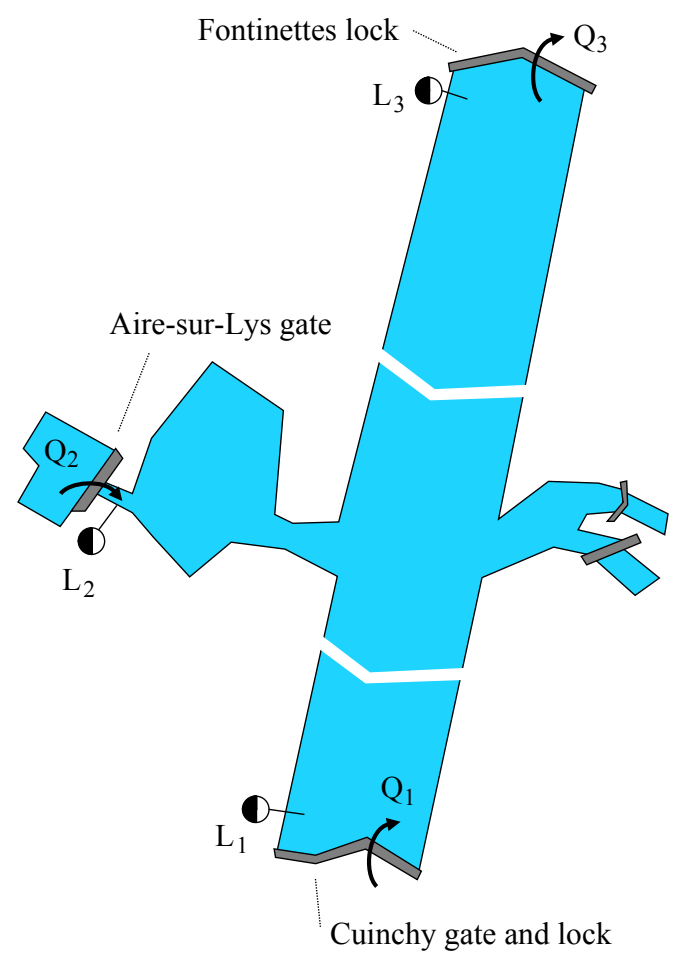

Figure 5: Scheme of the Cuinchy-Fontinettes navigation reach.

The Cuinchy lock is composed of a $2 \mathrm{~m}$ high chamber with a volume of $3700 \mathrm{~m}^{3}$. The maximum discharge which sypplies or empties the chamber is equal to $11 \mathrm{~m}^{3} / \mathrm{s}$. The chamber of the Fontinettes 


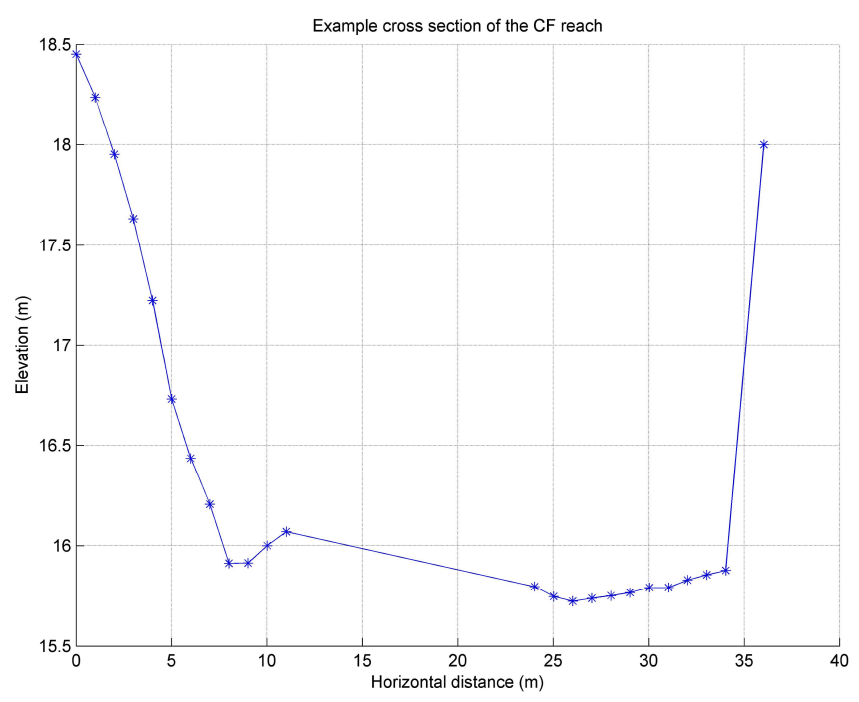

Figure 6: Example cross section of the CFR, with dots the measured points are shown.

lock is $13 \mathrm{~m}$ high with a volume of $25000 \mathrm{~m}^{3}$, and a maximum discharge equal to $30 \mathrm{~m}^{3} / \mathrm{s}$. The 158 control of Cuinchy and Fontinettes locks is constrained by the navigation demand. The valves that 159 supply and empty the lock chambers are controlled by the lock-keeper according to several conditions: 160 number of ships, size of ships, etc. Thus, the time of a lock operation, i.e. the discharge, is never the 161 same. In any case, the operation of the locks causes a wave phenomenon which impacts the CFR. In 162 particular, the operation of the Fontinettes lock can cause a wave with an amplitude which exceeds $13 \quad 163$ $\mathrm{cm}$. This wave is attenuated only after 2 hours.

\subsection{CFR modeling on SIC software}

The model proposed in (3) is based on the Saint-Venant equations. It is a simplified model of the CFR which is dedicated to the controller design to limit the impact of this wave. In (12), the proposed gray-box model is identified with data from the SIC-1D hydrodynamic model (26) by considering the CFR such as a channel with a rectangular profile. In this paper, the 614 transversal cross sections are considered. In order to implement the geometry of the CFR, measurement data is needed. The cross section data is stored as $x$ and $z$ coordinates: $x$ containing the horizontal distance and $z$ is the elevation. An example of the cross section to be implemented using SIC is shown in Figure 6. These 172 cross sections contain several data points, however in order to implement them using SIC the limit is 24 . Thus, the number of points in each cross section have been reduced to 24 points. Altogether 614 cross 


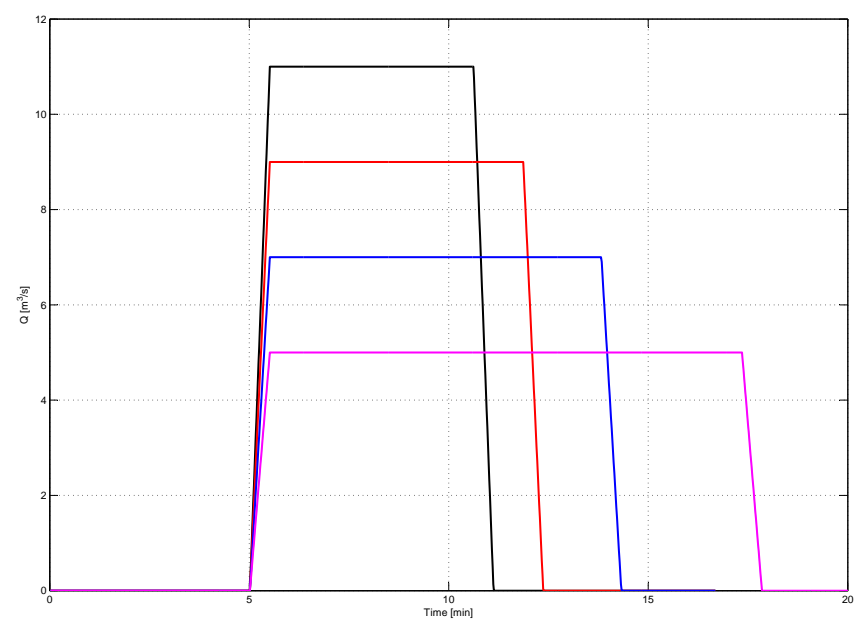

Figure 7: Cuinchy lock operations for different discharge schedules.

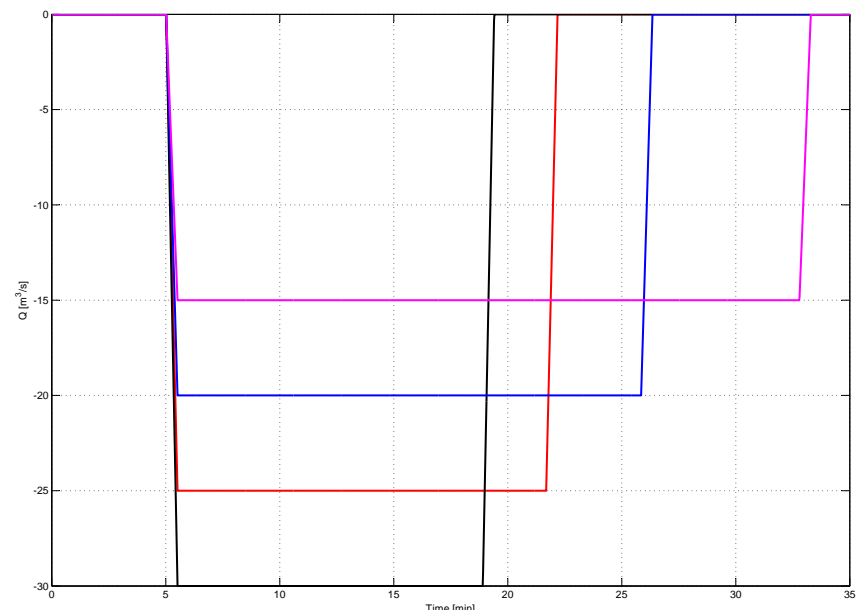

Figure 8: Fontinettes lock operations for different discharge schedules.

a trapezoidal pattern as shown in Figures 7 and 8 for Cuinchy and Fontinettes, respectively. Finally, SIC is used to reproduce the dynamics of the CFR, particularly the wave phenomenon. However, SIC is a deterministic model. It requires that all the data are known. In the real case, all the data are in general not available due to unknown inputs or outputs, noise etc. The gray-box modeling presents the advantage to deal with some uncertainties. In this paper, the gray-box model is valuated using data from SIC. 


\subsection{Gray-box modeling}

The CFR is a MIMO system with three inputs, $Q_{1}$ for Cuinchy, $Q_{2}$ for Aire-sur-la-Lys, and $Q_{3}$ for Fontinettes, i.e. $n_{u}=3$. The levels of the CFR are measured at three points; $L_{1}$ at Cuinchy, $L_{2}$ at Aire-sur-la-lys and $L_{3}$ at Fontinettes, i.e. $n_{y}=3$. The time-delays are determined according to relations $(3)$ and (4), with the mean cross sectional area $S$ and the maximum discharge $Q_{\max }$. The mean cross sectional area $S$ is computed according to the mean bottom width equal to $52 \mathrm{~m}$ and the water depth which corresponds to the NNL, i.e. $4.26 \mathrm{~m}$. The maximum discharge is evaluated according to the Fontinettes lock operation and is equal to $Q_{\max }=7.6 \mathrm{~m}^{3} / \mathrm{s}$. The matrices $\tau^{y}=\tau^{u}$ are given in minutes:

$$
\tau^{y}=\left[\begin{array}{ccc}
0 & 74 & 109 \\
75 & 0 & 35 \\
110 & 36 & 0
\end{array}\right]
$$

The vector $y_{k}$ is:

$$
y_{k}=\left[L_{1}(k) L_{2}(k) L_{3}(k)\right]^{T}
$$

and the vector $\bar{y}_{k \mid \tau^{y}}$ is given by:

$$
\begin{gathered}
\bar{y}_{k \mid \tau^{y}}=\left[L_{1}\left(k-\tau_{1,1}^{y}\right) L_{2}\left(k-\tau_{1,2}^{y}\right) L_{3}\left(k-\tau_{1,3}^{y}\right)\right. \\
L_{1}\left(k-\tau_{2,1}^{y}\right) L_{2}\left(k-\tau_{2,2}^{y}\right) L_{3}\left(k-\tau_{2,3}^{y}\right) \\
L_{1}\left(k-\tau_{3,1}^{y}\right) L_{2}\left(k-\tau_{3,2}^{y}\right) L_{3}\left(k-\tau_{3,3}^{y}\right]^{T}
\end{gathered}
$$

The vector $\bar{u}_{k \mid \tau^{u}}$ is:

$$
\begin{gathered}
\bar{u}_{k \mid \tau^{u}}=\left[Q_{1}\left(k-\tau_{1,1}^{u}\right) Q_{2}\left(k-\tau_{1,2}^{u}\right) Q_{3}\left(k-\tau_{1,3}^{u}\right)\right. \\
Q_{1}\left(k-\tau_{2,1}^{u}\right) Q_{2}\left(k-\tau_{2,2}^{u}\right) Q_{3}\left(k-\tau_{2,3}^{u}\right) \\
\left.Q_{1}\left(k-\tau_{3,1}^{u}\right) Q_{2}\left(k-\tau_{3,2}^{u}\right) Q_{3}\left(k-\tau_{3,3}^{u}\right)\right]^{T}
\end{gathered}
$$

The modeling approach consists in identifying the coefficients of the output and input matrices defined as:

$$
\begin{aligned}
A & =\left[\begin{array}{ccccccccc}
a_{1}^{1} & a_{2}^{1} & a_{3}^{1} & 0 & 0 & 0 & 0 & 0 & 0 \\
0 & 0 & 0 & a_{1}^{2} & a_{2}^{2} & a_{3}^{2} & 0 & 0 & 0 \\
0 & 0 & 0 & 0 & 0 & 0 & a_{1}^{3} & a_{2}^{3} & a_{3}^{3}
\end{array}\right] \\
B & =\left[\begin{array}{ccccccccc}
b_{1}^{1} & b_{2}^{1} & b_{3}^{1} & 0 & 0 & 0 & 0 & 0 & 0 \\
0 & 0 & 0 & b_{1}^{2} & b_{2}^{2} & b_{3}^{2} & 0 & 0 & 0 \\
0 & 0 & 0 & 0 & 0 & 0 & b_{1}^{3} & b_{2}^{3} & b_{3}^{3}
\end{array}\right]
\end{aligned}
$$



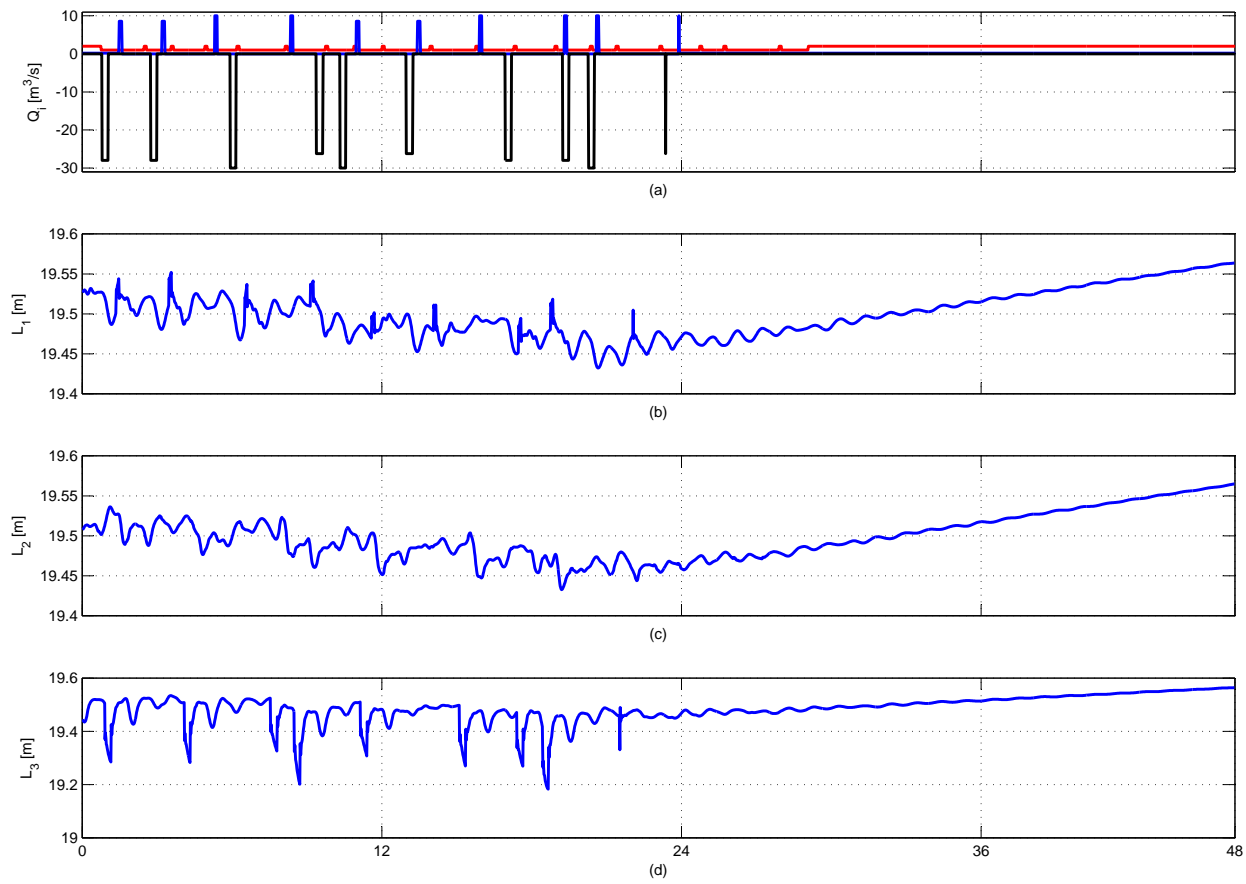

Figure 9: Scenario 1, (a) discharges at Cuinchy $Q_{1}$ (blue line), at Aire-sur-la-Lys $Q_{2}$ (red line) and at Fontinettes $Q_{3}$ (black line), levels at (b) Cuinchy $L_{1}$, (c) Aire-sur-la-Lys $L_{2}$ and (d) Fontinettes $L_{3}$.

\subsection{Identification of the CFR gray-box model}

The identification task consists in estimating the coefficients of the matrices $A$ and $B$ according to equations (11). To achieve this aim, the model of the CFR which is implemented using SIC is used to generate data. The proposed scenarios consist in the simulation of the lock and gate operations. The first scenario entitled 'scenario 1 ' is used for the identification of the matrices $A$ and $B$. It corresponds to two days of navigation with Cuinchy and Fontinettes lock operations. During these two days, the CFR is crossed by 10 ships. The time of the lock operations is different (see Figure 9.a). The CFR is also supplied by the gate at Aire-sur-la-Lys (see Figure 9 a). This discharge allows to maintain the NNL despite the Fontinettes operations. The Cuinchy lock operations cause wave phenomenon with a maximum amplitude of $8 \mathrm{~cm}$ (see Figure 9 b). The operations of the Fontinettes lock cause wave phenomenon along the CFR with an amplitude maximum equal to $13 \mathrm{~cm}$ (see Figure 9 d). This wave phenomenon is propagated along the CFR (see Figure 9.c). These signals obtained according to the SIC software are used to identify the model of the CFR. Due to the properties of the signals, the matrix $\left(\bar{\Phi} \bar{\Phi}^{T}\right)$ of the equation 11 can be singular. Thus it is often necessary to use the Moore-Penrose pseudoinverse of this matrix. Finally, the coefficients of the matrices $A$ and $B$ are given by Tables 1 and 2, respectively. After the identification step, the outputs of the model $\hat{y}_{k}$ and the measured levels 


\begin{tabular}{|c|c|c|c|c|c|c|c|c|}
\hline$a_{1}^{1}$ & $a_{2}^{1}$ & $a_{3}^{1}$ & $a_{1}^{2}$ & $a_{2}^{2}$ & $a_{3}^{2}$ & $a_{1}^{3}$ & $a_{2}^{3}$ & $a_{3}^{3}$ \\
\hline 8.73 & 1.16 & 0.11 & 0.44 & 9.43 & 0.14 & 0.92 & 1.26 & 7.81 \\
\hline
\end{tabular}

Table 1: Coefficients of the matrix $A\left(\times 10^{-1}\right)$.

\begin{tabular}{|c|c|c|c|c|c|c|c|c|}
\hline$b_{1}^{1}$ & $b_{2}^{1}$ & $b_{3}^{1}$ & $b_{1}^{2}$ & $b_{2}^{2}$ & $b_{3}^{2}$ & $b_{1}^{3}$ & $b_{2}^{3}$ & $b_{3}^{3}$ \\
\hline 1.14 & 0.78 & -0.09 & -0.08 & 0.23 & 0.05 & -0.14 & 3.48 & 1.75 \\
\hline
\end{tabular}

Table 2: Coefficients of the matrix $B\left(\times 10^{-3}\right)$.
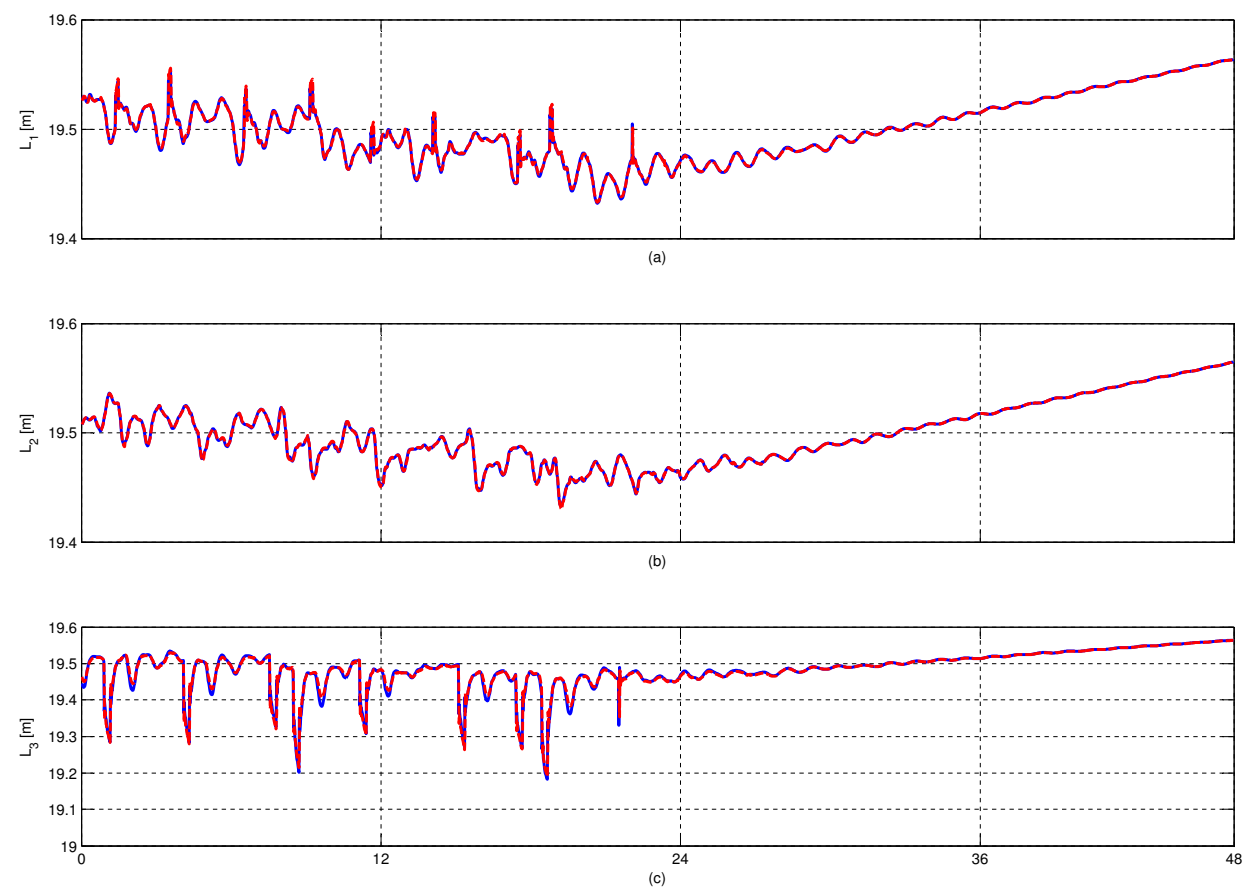

Figure 10: Scenario 1 - estimated (red dashed line) and measured (blue continuous line) levels at (a) Cuinchy $L_{1}$, (b) Aire-sur-la-Lys $L_{2}$ and (c) Fontinettes $L_{3}$.

$y_{k}=\left[\begin{array}{lll}L_{1}(k) & L_{2}(k) & L_{3}(k)\end{array}\right]^{T}$ are compared as depicted in Figure 10 The estimated ouputs in red dashed line are very close to the measured levels in blue continuous line. To estimate the effectiveness of the model, a fitting indicator (FIT) is defined as FIT $=\left(1-\frac{1}{N-T} \sum \frac{\|\hat{y}-y\|_{2}}{\left\|y-y_{m}\right\|_{2}}\right) \times 100$, where $y_{m}$ is a column vector composed of the mean value of $y$. For this scenario, the FIT is given for each level in 


\begin{tabular}{|c|c|c|}
\hline$F I T_{L_{1}}$ & $F I T_{L_{2}}$ & $F I T_{L_{3}}$ \\
\hline 92 & 98 & 81 \\
\hline
\end{tabular}

Table 3: FIT indicators for the 'scenario 1' (\%).

\begin{tabular}{|c|c|c||c|c|c|}
\hline \multicolumn{3}{|c||}{ 'scenario 2' } & \multicolumn{3}{c|}{ 'scenario 3' } \\
\hline$F I T_{L_{1}}$ & $F I T_{L_{2}}$ & $F I T_{L_{3}}$ & $F I T_{L_{1}}$ & $F I T_{L_{2}}$ & $F I T_{L_{3}}$ \\
\hline 85 & 95 & 75 & 83 & 94 & 75 \\
\hline
\end{tabular}

Table 4: FIT indicators for the 'scenario 2' and 'scenario 3' (\%).

\section{Evaluation of the CFR gray-box model}

The evaluation of the effectiveness of the CFR model is carried out according to several scenarios. All of these scenarios have not presented herein but two of them are detailed. The second scenario, entitled 'scenario 2', consists in the simulation of 2 days of navigation with the crossing of 7 ships the first day and 7 the second day according to the navigation scheduling. The time of the Cuinchy and Fontinettes lock operations is not the same during these two days (see Figure 11.a). The gate at Airesur-la-Lys is also opened to supply water to the CFR. The outputs of the model $\hat{y}_{k}$ and the measured levels $y_{k}$ are depicted in Figures 11.b, 11.c and 11. d for each level, in dashed red line and continuous blue line respectively. The gray-box outputs are close to the measured levels. It is confirmed by the errors $\epsilon_{y_{k}}=y_{k}-\hat{y}_{k}$ as shown in Figure 12. The third scenario, entitled 'scenario 3', consists in the simulation of 2 days of navigation. The CFR is also crossed by 7 ships the first day and 7 the second day. In this scenario, the time of the Cuinchy lock operations is the same whereas the Fontinettes lock operations are different (see Figure 13.a). The discharge in Aire-sur-la-Lys is controlled to supply the CFR. For each level, the outputs of the model $\hat{y}_{k}$ and the measured levels $y_{k}$ are depicted in Figure $13 \mathrm{~b}, 13 \mathrm{c}$ and $13 \mathrm{~d}$, in dashed red line and continuous blue line respectively. The errors $\epsilon_{y_{k}}$ between $\hat{y}_{k}$ and $y_{k}$ for 'scenario 3' are shown in Figure 14. In these two scenarios, the estimated outputs are close to the measured data, as shown the Figures 11 and 13 . The FIT indicators (see Table 4) confirm the effectiveness of the CFR gray-box model on these scenarios. Finally, the maximum of the absolute errors between the outputs of the model and the measured levels for both scenarios are given in Table 5 

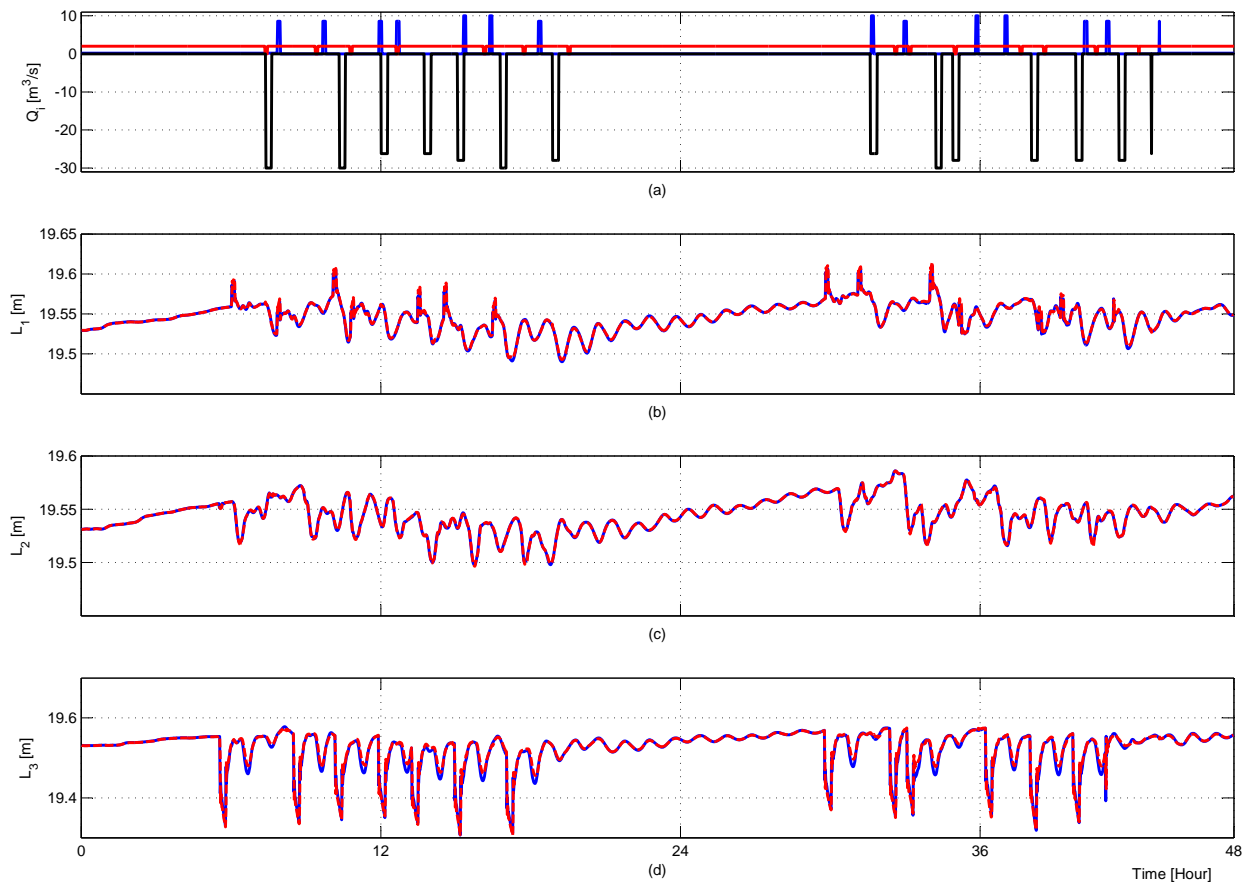

Figure 11: Scenario 2 of 2 navigation days with the Cuinchy lock and Fontinettes lock operations, (a) Discharges in Cuinchy (blue line), in Aire-sur-la-Lys (red line) and in Fontinettes (black line), and estimated (red dashed line) and measured (blue continuous line) levels at (b) Cuinchy $L_{1}$, (c) Aire-sur-la-Lys $L_{2}$ and (d) Fontinettes $L_{3}$.

\begin{tabular}{|c|c|c||c|c|c|}
\hline \multicolumn{3}{|c||}{ 'scenario 2' } & \multicolumn{3}{c|}{ 'scenario 3' } \\
\hline $\max \left(\left|\epsilon_{L_{1}}\right|\right)$ & $\max \left(\left|\epsilon_{L_{2}}\right|\right)$ & $\max \left(\left|\epsilon_{L_{3}}\right|\right)$ & $\max \left(\left|\epsilon_{L_{1}}\right|\right)$ & $\max \left(\left|\epsilon_{L_{2}}\right|\right)$ & $\max \left(\left|\epsilon_{L_{3}}\right|\right)$ \\
\hline 0.028 & 0.005 & 0.13 & 0.032 & 0.004 & 0.14 \\
\hline
\end{tabular}

Table 5: Maximum of the absolute errors between the outputs of the model and the measured levels for the 'scenario 2' and 'scenario 3' in meter $[m]$.

\section{Conclusion}

The gray-box model proposed in this paper is used to reproduce the dynamics of inland navigation reaches in particular the wave phenomenon. It requires a good estimation of the time-delays characterizing the dynamics of the open-channel system. Then, according to available data from measurement or obtained from a simulation software based on the Saint-Venant equations, the parameters of the gray-model are identified. Finally, the identified model is evaluated according to other data. The proposed approach is applied on the Cuinchy-Fontinettes reach located in the north of France. This reach 

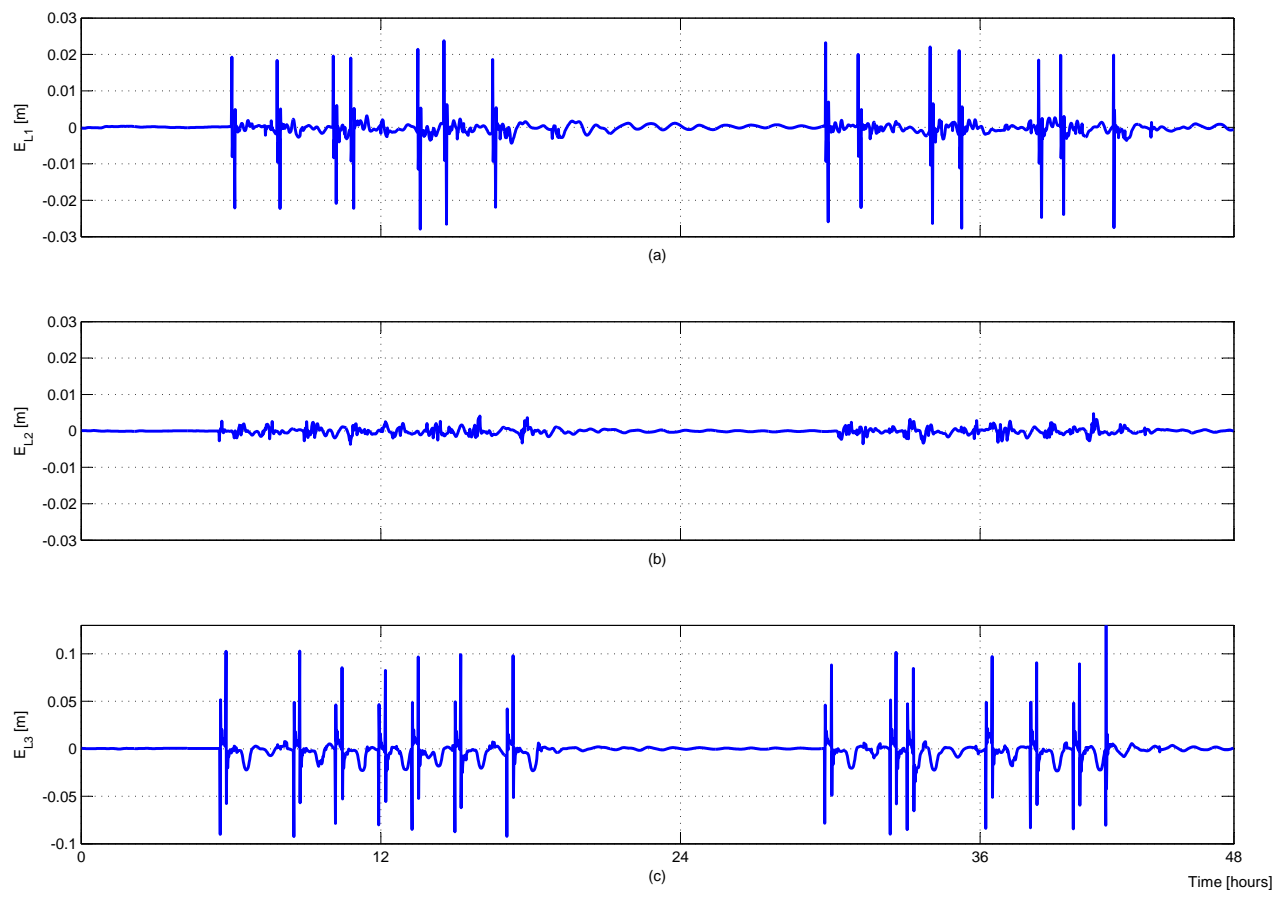

Figure 12: Scenario 2 - Errors between the outputs of the model and the measured levels, (a) $\epsilon_{L_{1}}(k)$ Cuinchy, (b) $\epsilon_{L_{2}}(k)$ - Aire-sur-la-Lys, and (c) $\epsilon_{L_{3}}(k)$ - Fontinettes.

is a large system equipped with locks and gates. It is impacted by wave phenomenon due to the lock operations. The identification approach is performed according to data from the SIC software that computes the numerical solution of the Saint-Venant equations. The real transversal cross sections of the Cuinchy-Fontinettes reach have been implemented. Then, the effectiveness of the identified model is evaluated by considering several scenarios of navigation. The future improvements will consist in dealing with real data which are measured on the Cuinchy-Fontinettes reach. Since now, the proposed gray-box model can be used to design control algorithms or Fault Detection and Isolation techniques. The reliability of the inland navigation networks in a global change context can also be studied.

\section{Acknowledgment}

This work is a contribution to the GEPET'Eau project which is granted by the French ministery MEDDE - GICC, the French institution ORNERC and the DGITM. 

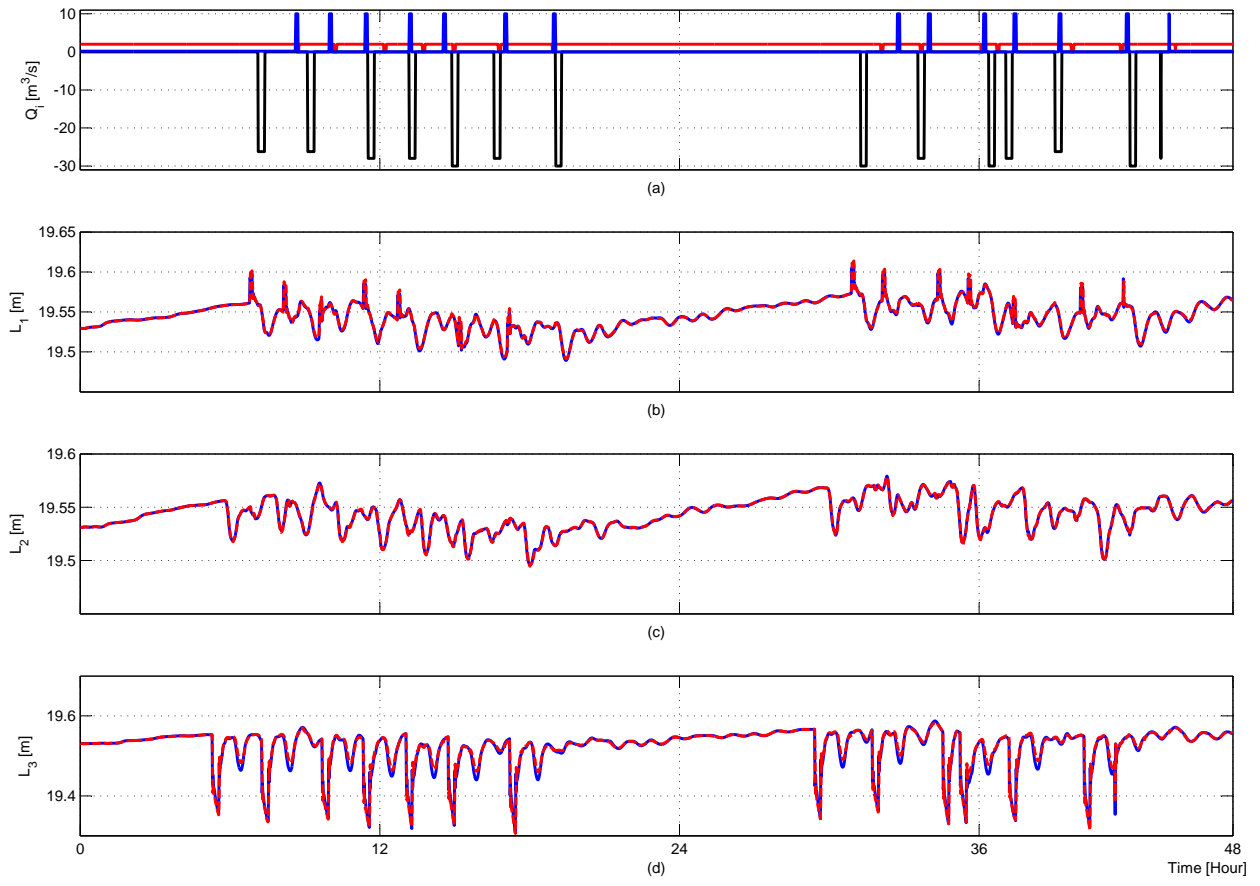

Figure 13: Scenario 3 of 2 navigation days with the Cuinchy lock and Fontinettes lock operations, (a) Discharges in Cuinchy (blue line), in Aire-sur-la-Lys (red line) and in Fontinettes (black line), and estimated (red dashed line) and measured (blue continuous line) levels at (b) Cuinchy $L_{1}$, (c) Aire-sur-la-Lys $L_{2}$ and (d) Fontinettes $L_{3}$.

\section{References}

[1] S. Amin, X. Litrico, S. Sastry and A. Bayen, Cyber security of water SCADA systems: (I) Analysis and experimentation of stealthy deception attacks, IEEE Transactions on Control Systems Technology, 2012.

[2] B.P. Arkell and G.J.C. Darch, Impact of climate change on London's transport network, Proceedings of the ICE-Municipal Engineer, Volume 159, Issue 4, Pages 231-237, 2006.

[3] J. Blesa, E. Duviella, M. Sayed-Mouchaweh, V. Puig and K. Chuquet, Automatic control to improve the seaworthiness conditions in inland navigation networks: application to a channel in the 2012.

[4] J. Boé, L. Terray, E. Martin and F. Habetsi, Projected changes in components of the hydrological 

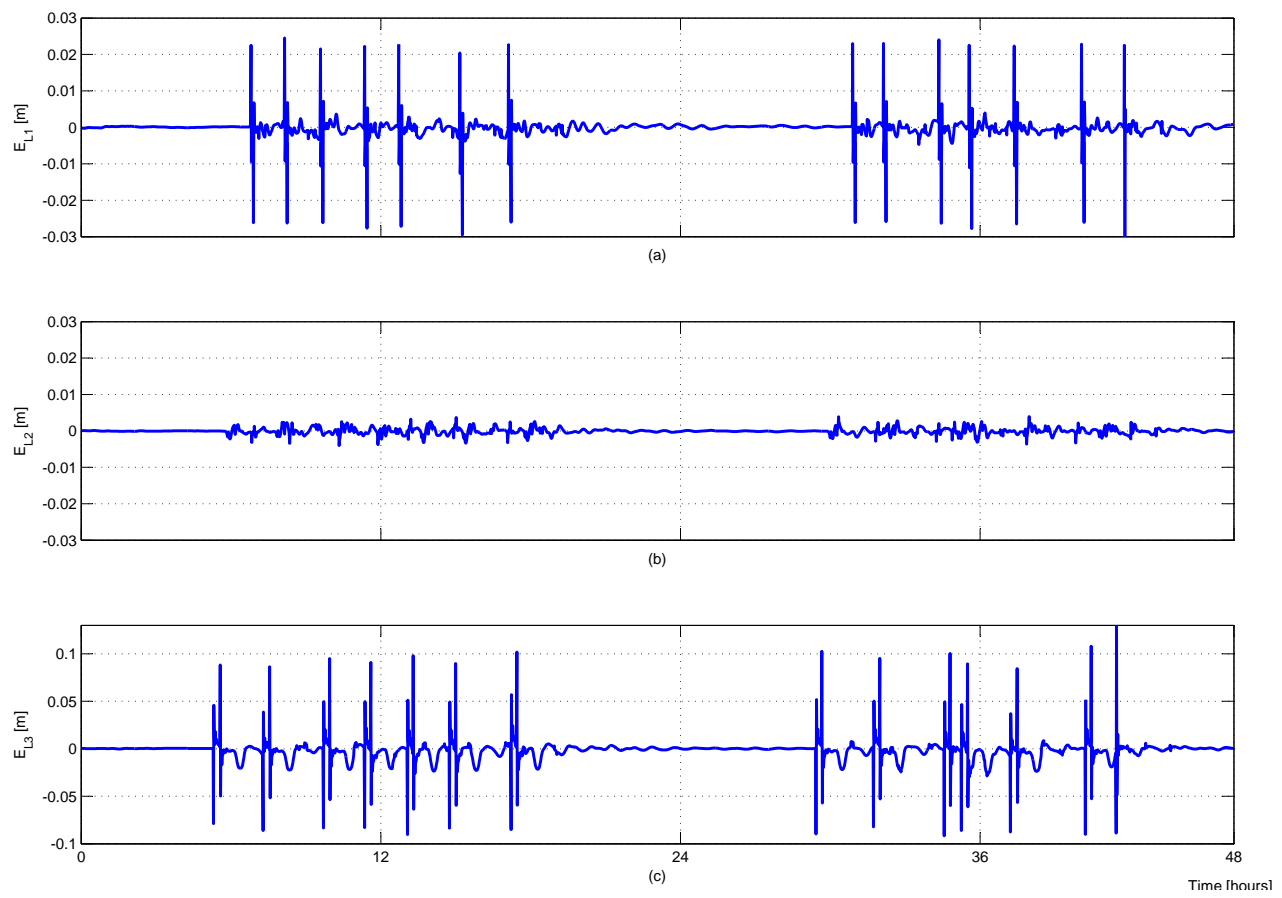

Figure 14: Scenario 3 - Errors between the outputs of the model and the measured levels, (a) $\epsilon_{L_{1}}(k)$ Cuinchy, (b) $\epsilon_{L_{2}}(k)$ - Aire-sur-la-Lys, and (c) $\epsilon_{L_{3}}(k)$ - Fontinettes.

[5] C. Brand, M. Tran and J. Anable, The UK transport carbon model: An integrated life cycle approach to explore low carbon futures, Energy Policy, Volume 41, Pages 107-124, February 2012.

[6] I.A.A. Ten Broeke, C.P.M. Willems and C.C. Glansdorp, A joint European effort to enhance safety and usability of the inland waterway network, In 2001 IEEE Intelligent Transportation Systems Conference Proceedings, Oakland (CA) USA August 2001.

[7] V. Bugarski, T. Backalic and U. Kuzmanov, Fuzzy decision support system for ship lock control, Expert Systems with Applications, Volume 40, Issue 10, Pages 3953-3960, August 2013.

[8] V. T. Chow, (1959). Open-channel hydraulics, McGraw-Hill. New York.

[9] E.F. Camacho and C. Bordons, Model Predictive Control, Springer, Great Britain, 2004.

[10] E.G.R. Davies and S.P. Simonovic, Global water resources modeling with an integrated model of the social-economic-environmental system. Advances in water resources, Volume 34, Pages 684700, 2011.

[11] A. Ducharne, F. Habets, C. Pagé, E. Sauquet, P. Viennot, M. Déqué, S. Gascoin, A. Hachour, E. 
Martin, L. Oudin, L. Terray and D. Thiéry, Climate change impacts on Water Resources and Hy-

[12] E. Duviella, J. Blesa, L. Bako, Y. Bolea, M. Sayed-Mouchaweh, V. Puig and K. Chuquet, Inland navigation channel model: Application to the Cuinchy-Fontinettes reach, International Conference on Networking, Sensing and Control, ICNSC, Paris-Evry University, France, April 10-12 2013.

[13] E. Duviella, L. Rajaoarisoa, J. Blesa and K. Chuquet, Adaptive and predictive control architecture of inland navigation networks in a global change context: application to the Cuinchy-Fontinettes Petersburg, Russia, June 19-21 2013.

[14] E. Duviella, L. Rajaoarisoa, J. Blesa and K. Chuquet, Fault Detection and Isolation of inland navigation channel: Application to the Cuinchy-Fontinettes reach, 52nd IEEE Conference on Decision and Control, Florence, Firenze, Italy, December 10-13 2013.

[15] EnviCom - Task Group 3, Climate Change and Navigation - Waterborne transport, ports and waterways: A review of climate change drivers, impacts, responses and mitigation, EnviCom TG 3 - Issue 2008.

[16] M. Fastenbauer, M. Sattler and G. Schilk, River Information Services for commercial users in the Inland Waterway sector, In proceedings International Symposium on Logistics and Industrial Informatics. Wildau, Germany, 2007.

[17] J. M. Garcia-Ruiz, J.I. Lopez-Moreno and S. M. Vicente-Serrano, Mediterranean water resources in a global change scenario, Earth-Science Reviews, Volume 105, Pages 121-139, 2011.

[18] N. Graveline, S. Loubier, G. Gleyses and J.D. Rinaudo, Impact of farming on water resources: Assessing uncertainty with Monte Carlo simulations in global change context, Agricultural systems, Volume 108, Pages 29-41, 2012.

[19] IWAC Inland Waterways Advisory Council,Climate change mitigation and adaptation. Implications for inland waterways in England and Wales, 2009. 
[21] X. Litrico and V. Fromion, Simplified modeling of irrigation canals for controller design. Journal of Irrigation and Drainage Engineering, Vol. 130, No. 5, pp. 373-383, 2004.

[22] X. Litrico, P.O. Malaterre, Test of auto-tuned automatic downstream controllers on Gignac Canal, second Conference on SCADA and Related Technologies for Irrigation System Modernization - A USCID Water Management Conference, Denver, Colorado, June 6-9, 2007.

[23] X. Litrico and V. Fromion, Modeling and Control of Hydrosystems, Springer, 2009.

[24] L. Ljung, System identification: Theory for the user, Prentice-Hall. Englewood Cliffs, N.J, 1987.

[25] J.M. Maciejowski, Predictive Control: With Constraints. Prentice Hall, 2002.

[26] P. O. Malaterre, SIC 5.20, Simulation of irrigation canals, http://www.cemagref.net/sic/sicgb.htm, 2006.

[27] P. O. Malaterre and C. Chateau, SCADA interface of the SIC software for easy real time application of advanced regulation algorithms, second Conference on SCADA and Related Technologies for Irrigation System Modernization - A USCID Water Management Conference, Denver, Colorado, June 6-9, 2007.

[28] I. Mallidis, R. Dekker and D. Vlachos, The impact of greening on supply chain design and cost: a case for a developing region, Journal of Transport Geography, Volume 22, Pages 118-128, May 2012.

[29] S. Mihic, M. Golusin and M. Mihajlovic, Policy and promotion of sustainable inland waterway transport in Europe - Danube River, Renewable and Sustainable Energy Reviews, Volume 15, Issue 4, Pages 1801-1809, May 2011.

[30] S.J. Murray, P.N. Foster and I.C. Prentice, Future global water resources with respect to climate change and water withdrawals as estimated by a dynamic global vegetation model, Journal of Hydrology, Volume 448-449, Pages 14-29, 2012.

[31] T. Rabbani, S. Munier, D. Dorchies, P.-O. Malaterre, A. Bayen and X. Litrico, Flatness-based control of open-channel flow in an irrigation canal using SCADA, IEEE Control Systems Magazine, Volume 29, No. 5, Pages 22-30, 2009.

[32] M. Rijo and C. Arranja, Supervision and water depth automatic control of an irrigation canal, Journal of Irrigation and Drainage Engineering, Volume 136, No. 1, Pages 3-10, 2010 
[33] K. Tan, Y. Li, P. Gawthrop and A. Glidle, Evolutionary Grey-Box modelling for Practical Systems, Technical Report CSC-96019, Centre for Systems and Control, University of Glasgow, 1997.

[34] P.Y. Vion, V. Kulesza and P.O. Malaterre, Modernization project and scientific platform on the

[35] S. Wang, S. Kang, L. Zhang, and F. Li, Modelling hydrological response to different land-use and Volume 22(14), Pages 2502-2510, 2007.

[36] Ian White Associates, Cheviot House, Shaw Lane, Beckwithshaw, HARROGATE, HG3 and 1QZ, 334 Report for the Inland Waterways Advisory Council Information and Communication Technology 335 for the UK's Inland Waterways, Technical report, July 2008. 